
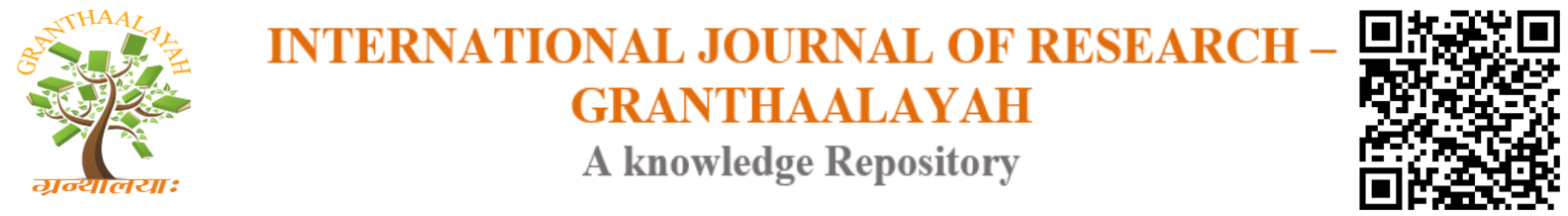

Science

\title{
IMPACT OF NUTRITION DURING PREGNANCY UPON HEALTH OF PREGNANT WOMEN
}

\author{
Pratiksha Mishra $^{1}$, Dr. Nirmal Kaur ${ }^{2}$, Miss Neha Qumar ${ }^{3}$ \\ ${ }^{1}$ M.Sc Student, Pushp Institute of Sciences \& Higher Studies, Pilibhit, UP, INDIA \\ ${ }^{2}$ Assistant professor, Pushp Institute of Sciences \& Higher Studies, Pilibhit, UP, INDIA \\ ${ }^{3}$ Lecturer, Pushp Institute of Sciences \& Higher Studies, Pilibhit, UP, INDIA
}

DOI: https://doi.org/10.29121/granthaalayah.v4.i8.2016.2579

\section{ABSTRACT}

Pregnancy is a period of considerable physiological and nutritional stress, during which the maternal requirements of almost all the nutrients are greatly increased. Pregnant women are considered as a vulnerable group because of increased physiological demands. Diet during pregnancy is one of the most important factors in achieving a successful outcome of pregnancy in terms of healthy baby and maintenance of her own health, as the overall development of child is determined to a great extent by the type of nourishment it receives right from the conception. By keeping in mind about the importance of nutritional diet the study was conducted with following objectives i.e. to study the knowledge about diet amongst pregnant women as well as diet taken by pregnant women (24 hour dietary recall) health problems among pregnant women as well as comparison between RDA and actual intake of nutrients. Results showed that near about $50 \%$ respondents has no idea about which nutrient rich diet should be taken during pregnancy. On the basis of 24 hour dietary recall it was found that more than 60\% respondents do not gave importance to the inclusion of pulses, cereal, green leafy vegetables, fruits and milk in their diet. Besides this it was also found that 63.33 \%respondents were having low hemoglobin level. There were $63.33 \%$ women having low blood pressure and $16.66 \%$ were having high blood pressure. In case of blood sugar level it was found that $60 \%$ were having low sugar level and $26.66 \%$ were having high level.

Keywords:

Nutrient intake, Pregnant women, Pregnancy, 24 hour dietary recall, RDA.

Cite This Article: Pratiksha Mishra, Dr. Nirmal Kaur, and Miss Neha Qumar, "IMPACT OF NUTRITION DURING PREGNANCY UPON HEALTH OF PREGNANT WOMEN" International Journal of Research - Granthaalayah, Vol. 4, No. 8 (2016): 188-195.

\section{INTRODUCTION}

Pregnancy is a time of tremendous physiological change that demands healthy dietary life style choices. Growing fetus draws a lot of energy and nutrients from the mother, to enhance physical 
and psychological development [1] It is a period of considerable physiological \& nutritional stress, during which the maternal requirement of almost all the nutrients are greatly increased. Pregnant women are considered as a vulnerable group because of increased physiological demands [2]. The health of the mother and her nutritional status can influence the health and survival of the child because of the biological links that exist between her and child during pregnancy and lactation [3].

Malnutrition has been recognized as one of the underlying factor for maternal death during the process of procreation. The causes of malnutrition are multidimensional and multi-factorial with poverty, food inadequacy and maternal illiteracy being the main culprit of the menace in developing countries. [4].

In well-nourished women, optimal weight gain and outcome of pregnancy can be attained over a very wide range of energy intakes. Many women sustain a pregnancy with a successful outcome on less than the recommended energy intake. This probably reflects different adoptive strategies that can be used to meet the additional energy demands of pregnancy, as following: intake can be increased, nutrients can be more efficiently used, by increasing absorption or by reducing excretion, BMR may be reduced, diet induced thermo genesis can be reduced. Physical activity can be reduced growth in new tissue or fat deposition in maternal stores can be reduced. Energy requirement increase in pregnancy by about 12 percent. This is because of the increase in maternal body weight, an average 10-15 per cent increase in basal metabolic rate (BMR).

Maternal nutrition before and during pregnancy is an important determinant of birth weight. High rate of Low Birth Weight (LBW) in developing countries has been attributed to poor maternal nutrition. Pregnancy is a time of tremendous physiological change that demands healthy dietary lifestyle choices. Growing fetus draws a lot of energy and nutrients from the mother to enhance physical and psychological development [5]. In developing countries such as Nigeria, it is paramount to states that low birth weight stems primarily from the mother's poor health and nutrition, and inadequate nutrition during pregnancy accounts for a large proportion of growth retardation.

The normal protein requirement of an adult woman is $50 \mathrm{~g} / \mathrm{day}$. ICMR prescribed for pregnant women $65 \mathrm{~g} / \mathrm{day}$. Additional protein is essential for rapid growth of the fetus, the enlargement of the uterus, mammary glands and placenta, formation of amniotic fluid and storage reserves for labor, delivery and lactation. The amount of dietary calcium needed is reduced when vitamin $\mathrm{D}$ is available. Use of vitamin D and calcium reduces muscular cramps of pregnancy. To prevent 'osteomalacia' mother's diet should contain less of phytic acid, adequate amounts of vitamin D and sufficient amount of calcium. Mother should avoid repeated pregnancies. The increase in iron by $8 \mathrm{mg} /$ day can be attributed to the high $\mathrm{Hb}$ levels of $18-22 \mathrm{~g} / 100 \mathrm{ml}$ of blood iron stores in the liver of the infant lasts from 3 to 6 month. Iron is also required for growth of fetus and placenta, loss of maternal iron through skin and sweat is about $170 \mathrm{mg}$ of iron.[6]. 


\section{MATERIAL AND METHODS}

\subsection{CONSTRUCTION OF TOOL}

A preliminary survey along with observation was conducted in district hospital of Pilibhit to develop a rapport with pregnant women and become aware with the problems faced by asking informal questions from them. The interview schedule was prepared and divided into two parts for collection of data. First part of the interview schedule dealt with the general information which included name, age, and weight of the respondents. In the second part of the interview schedule, the investigator has asked about diet pattern and health problems of the pregnant women.

\subsection{SELECTION OF SAMPLES}

Purposive random sampling design was used to select the study area and respondents. A sample of 30 pregnant women was selected from the age group of 30-40 years.

\subsubsection{SELECTION OF LOCALE}

To study the assessment of nutritional health of pregnant women, present study was carried out in District hospital, Pilibhit. The main reason of selection of this locale was that it was easily approachable for the researcher and total sample size was also available in this area.

\subsection{METHOD OF DATA COLLECTION}

The following health problems were measured with the help of relative instruments.

- Hemoglobin

- Blood Pressure

- Blood Sugar

- Weight

\subsubsection{HEMOGLOBIN}

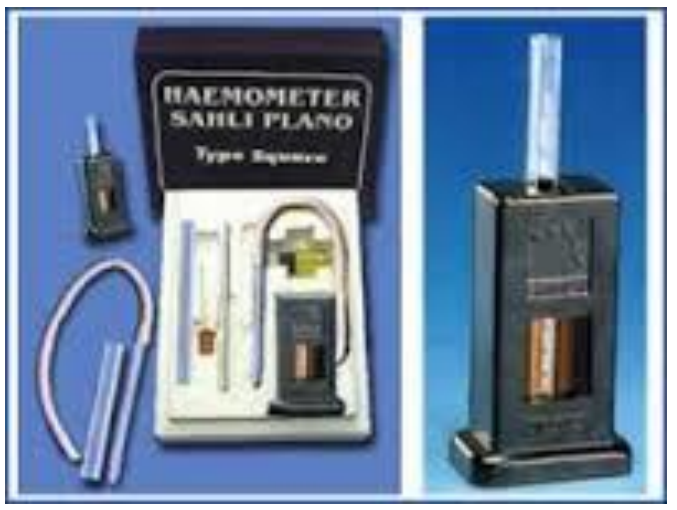

Hemoglobin is estimated by Sahlish Method with the principle that the amount of hemoglobin can be estimated by the conversion of known volume of blood into acid- hametin by the Adison dilution and subsequent calorimetric comparison with a suitable standard. With the help of dropper take N/10 HCL in a graduated hemoglobinometry tube upto its lowest mark (2gm/dl). Drop $20 \mu$ lit. of blood into the pipette taking care that there should be no air bubbles. Immediately transfer the blood from pipette into the N/10 HCL in a graduated hemoglobinometry tube and raise the pipette several times by drawing the N/10 HCL used for mixing the blood. Mix the content thoroughly and leave the solution to stand for about a minute for the maximum conversion of hemoglobin in blood to acid- haematin. Dilute the acid heamatin by adding distilled water and stir it thoroughly. Continue dilution till its colour matches with that of standard. Note the reading on the hemoglobinometer tube and express the hemoglobin content as gm / 100ml of blood. (Figure 1: Hemoglobinometry) 


\subsubsection{BLOOD PRESSURE}

Many things can make blood pressure rise for a short time. Make sure that a person does not need to use the toilet, and that he/she has not just eaten a big meal. Do not measure the blood pressure within 30 minutes of drinking caffeine. Person should wear loose-fitting clothes like a short sleeved t-shirt so that sleeves can be pushed up comfortably. Always use the same arm for blood pressure readings, as each arm will give a

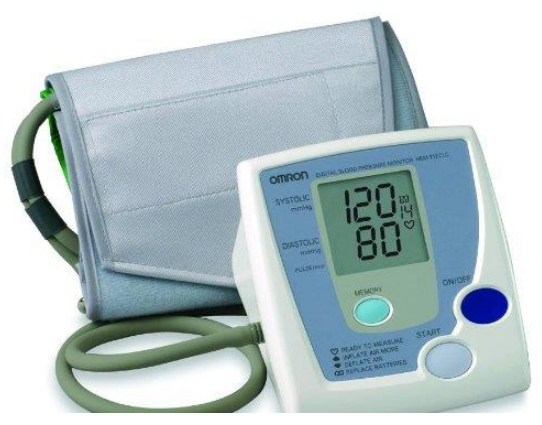
slightly different reading. If possible, use the arm that your doctor or nurse uses when measuring your blood pressure. Before taking the readings, person should allow to take rest for five minutes. Person should be sitting down in a quiet place, preferably at a desk or table, with his/her arm resting on a firm surface and their feet should be flat on the floor. The band should be tied around the upper arm just one inch above the inner center of the elbow than it should be connected to the digital monitor screen. Press the button to take the reading and note down it (Figure 2: Digital Blood Pressure Monitor)

\subsubsection{BLOOD SUGAR}

Firstly prepare a test strip. Choose the spot-don't check from the same finger all the time. Prepare the lancing device and get a drop of blood from the side of your fingertip or other approved site. Check the blood sugar by touching and holding the test strip opening to the drop until it has absorbed enough blood to begin the test. Turn on the meter and view the test result.

(Figure 3: Digital Blood Pressure Machine)

\subsubsection{WEIGHT}

Weighing Balance was used to measure the body weight in kilogram of an individual with minimum clothes and accessories on the body (Figure 4: Weighing Balance)

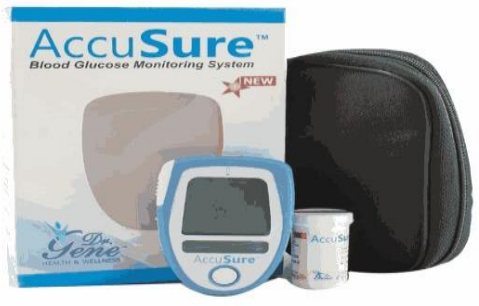

\section{RESULT AND DISCUSSION}

It was tried to investigate from the respondents that do they know about which type of diet should be taken during pregnancy than it was found that only $23.3 \%$ know that protein rich diet should be taken in this period where as $46.6 \%$ were having no idea about it data shown in table1 showed that maximum respondent $40 \%$ were not knowing about iron rich diet and $46.6 \%$ were undecided about calcium rich diet. Only $16.6 \%$ were agree that fiber rich diet should be taking during the pregnancy where as $20 \%$ and $23.3 \%$ told that vitamin rich diet and energy rich diet should be taken in this period respectively. 
Table 1: Knowledge about diet should be taken during pregnancy

\begin{tabular}{|l|l|c|c|c|c|c|c|}
\hline S.No. & \multicolumn{2}{|c|}{ Content } & \multicolumn{2}{|c|}{ Agree } & \multicolumn{2}{c|}{ Disagree } & \multicolumn{2}{c|}{ Undecided } \\
\cline { 3 - 8 } & & F & \% & F & \% & F & $\%$ \\
\hline 1. & Protein rich diet & 7 & 23.3 & 9 & 30 & 14 & 46.6 \\
\hline 2. & Iron rich diet & 8 & 26.6 & 10 & 33.3 & 12 & 40 \\
\hline 3. & Calcium rich diet & 7 & 23.3 & 9 & 30 & 14 & 46.6 \\
\hline 4. & Fiber rich diet & 5 & 16.6 & 8 & 26.6 & 17 & 56.6 \\
\hline 5. & Vitamin rich diet & 6 & 20 & 11 & 36.6 & 13 & 43.3 \\
\hline 6. & Energy rich diet & 7 & 23.3 & 8 & 26.6 & 15 & 50 \\
\hline
\end{tabular}

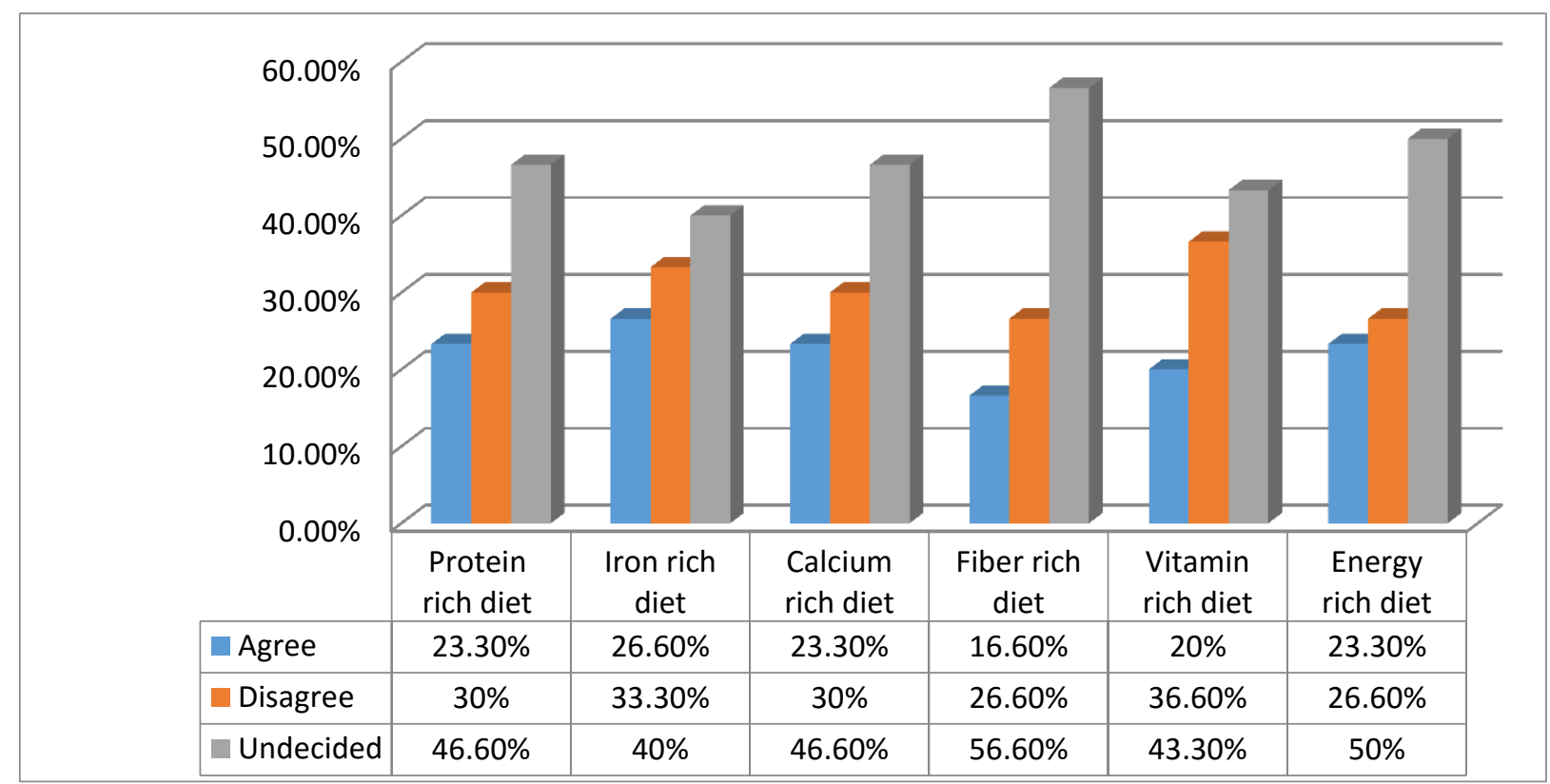

Figure 5: Knowledge about Diet among Pregnant Women

On the basis of 24 hour dietary recall it was found that only $13.3 \%$ women consume pulses daily in their meal and $10 \%$ include cereals and salad daily in their meal, whereas only $6.66 \%$ were those who took fruits and milk daily as shown in Figure-6.

Table 2: Diet taken by pregnant women (on the basis of 24 hour dietary recall)

\begin{tabular}{|l|l|c|c|c|c|c|c|}
\hline \multirow{2}{*}{ S.No. } & \multirow{2}{*}{ Content } & \multicolumn{2}{|c|}{$\begin{array}{c}\text { Daily } \\
\text { (in one meal) }\end{array}$} & \multicolumn{2}{c|}{$\begin{array}{c}\text { Alternative } \\
\text { (in one meal) }\end{array}$} & \multicolumn{2}{c|}{$\begin{array}{c}\text { Not included } \\
\text { (in last 3 days) }\end{array}$} \\
\cline { 3 - 8 } & & F & \% & F & \% & F & \% \\
\hline 1. & Pulses & 4 & 13.3 & 6 & 20 & 20 & 66.6 \\
\hline 2. & Cereals & 3 & 10 & 8 & 26.6 & 19 & 63.3 \\
\hline
\end{tabular}




\begin{tabular}{|l|l|c|c|c|l|l|l|}
\hline 3. & Fruits & 2 & 6.66 & 5 & 16.6 & 23 & 76.6 \\
\hline 4. & GLV'S & - & - & 7 & 23.3 & 23 & 76.6 \\
\hline 5. & Milk & 2 & 6.66 & 6 & 20 & 22 & 73.3 \\
\hline 6. & Salad & 3 & 10 & 5 & 16.6 & 24 & 76.6 \\
\hline
\end{tabular}

\begin{tabular}{|l|c|c|c|c|c|c|c|}
\hline & & & & \\
\hline
\end{tabular}

Figure 6: Diet Taken by Pregnant Women

As we can saw that the respondents were having very low level of nutritional knowledge during pregnancy that's why only $23.3 \%$ were there, taking adequate amount of protein per day whereas rest of the respondents were not and there were $26.6 \%$ women who were taking adequate amount of Iron. In case of vitamin A only $40 \%$ of respondent were taking adequate amount per day whereas rest of respondent were not and there were $24.4 \%$ women who were taking adequate intake of ascorbic acid and 53.33\% were taking adequate amount of folic acid per day where rest of the respondents were not taking adequate amount per day as compared from RDA values as shown in Table-3.

Due to poor nutrient intake lots of health problems were found amongst the target group which can be seen in Table-4 as $63.33 \%$ were having low levels of hemoglobin and there were $63.33 \%$ women suffering from low blood pressure as well as $16.66 \%$ as high blood pressure. When the blood sugar was checked amongst them then it was found that $60 \%$ were having low and $26.66 \%$ were having high level as both the things were risky for mother as well as for baby.

Table 3: Comparison between RDA and actual intake by Pregnant Women

\begin{tabular}{|l|l|l|l|l|}
\hline S.No. & Nutrients & $\begin{array}{l}\text { Adequate intake } \\
\text { per day }(\%)\end{array}$ & $\begin{array}{l}\text { Inadequate } \\
\text { intake per } \\
\text { day }(\%)\end{array}$ & RDA \\
\hline
\end{tabular}




\begin{tabular}{|l|l|l|l|l|}
\hline 1. & Protein & $23.3 \%$ & $76.7 \%$ & $65 \mathrm{~g} /$ day \\
\hline 2. & Iron & $26.6 \%$ & $73.4 \%$ & $38 \mathrm{mg} /$ day \\
\hline 3. & Calcium & $23.3 \%$ & $76.7 \%$ & $1000 \mathrm{mg} /$ day \\
\hline 4. & Energy & $23.3 \%$ & $76.7 \%$ & $2525 \mathrm{kcal} /$ day \\
\hline 5. & Vit. A & $40 \%$ & $60 \%$ & $2400 \mu \mathrm{g} /$ day \\
\hline 6. & Ascorbic acid & $24.4 \%$ & $75.6 \%$ & $40 \mathrm{mg} /$ day \\
\hline 7. & Folic acid & $53.33 \%$ & $46.67 \%$ & $400 \mu \mathrm{g} /$ day \\
\hline
\end{tabular}

Table 4: Health problems among Pregnant Women during Pregnancy

\begin{tabular}{|c|c|c|c|c|c|c|c|c|}
\hline \multirow[t]{2}{*}{ S.No } & \multirow[t]{2}{*}{ Content } & \multicolumn{7}{|c|}{ Level } \\
\hline & & \multicolumn{4}{|c|}{$\begin{array}{l}\text { Low } \\
(>)\end{array}$} & \multicolumn{3}{|c|}{$\begin{array}{l}\text { Appropriate } \\
(\mathbf{1 2 - 1 5} \text { g/dl })\end{array}$} \\
\hline \multirow[t]{4}{*}{1.} & \multirow[b]{2}{*}{ Hemoglobin } & $\mathbf{F}$ & & \multicolumn{2}{|l|}{$\%$} & \multicolumn{2}{|l|}{ F } & $\%$ \\
\hline & & 19 & & \multicolumn{2}{|c|}{63.33} & \multicolumn{2}{|l|}{11} & 36.66 \\
\hline & & \multicolumn{7}{|c|}{ Level } \\
\hline & & \multicolumn{3}{|c|}{\begin{tabular}{|l|} 
Low \\
$(90 / 60 \mathrm{~mm} / \mathrm{hg})$
\end{tabular}} & \multicolumn{2}{|c|}{\begin{tabular}{|l|l|} 
Normal \\
(120/80mm/hg)
\end{tabular}} & \multicolumn{2}{|c|}{$\begin{array}{l}\text { High } \\
(160-100 \mathrm{~mm} / \mathrm{hg})\end{array}$} \\
\hline \multirow[t]{4}{*}{2.} & \multirow{2}{*}{ Blood pressure } & $\mathbf{F}$ & \multicolumn{2}{|l|}{$\%$} & $\mathbf{F}$ & $\%$ & $\mathbf{F}$ & $\%$ \\
\hline & & 19 & \multicolumn{2}{|c|}{63.33} & 6 & 20 & & 16.66 \\
\hline & & \multicolumn{7}{|c|}{ Level } \\
\hline & & \multicolumn{3}{|c|}{$\begin{array}{l}\text { Low } \\
(130 \mathrm{mg} / \mathrm{dl})\end{array}$} & \multicolumn{2}{|c|}{\begin{tabular}{|l} 
Normal \\
( 108mg/dl )
\end{tabular}} & \multicolumn{2}{|c|}{$\begin{array}{l}\text { High } \\
(\quad 140 \mathrm{mg} / \mathrm{dl}\end{array}$} \\
\hline \multirow[t]{2}{*}{3.} & \multirow[b]{2}{*}{$\begin{array}{l}\text { Blood } \\
\text { sugar }\end{array}$} & $\mathbf{F}$ & $\%$ & & $\mathrm{~F}$ & $\%$ & $\mathbf{F}$ & $\%$ \\
\hline & & 18 & \begin{tabular}{|l|}
60 \\
\end{tabular} & & & \begin{tabular}{|l}
13.33 \\
\end{tabular} & 8 & 26.66 \\
\hline
\end{tabular}

Table 5: Weight gain amongst Pregnant Women during Pregnancy

\begin{tabular}{|c|c|c|c|c|c|c|c|c|}
\hline \multirow[t]{2}{*}{ Weight gain during pregnancy } & \multicolumn{2}{|c|}{$\begin{array}{l}\text { Uderweight } \\
\text { ( 12.2-18 Kg) } \\
\mathrm{N}=13\end{array}$} & \multicolumn{2}{|c|}{\begin{tabular}{|l|} 
Normal \\
$(11.5-16 ~ K g)$ \\
N=12
\end{tabular}} & \multicolumn{2}{|c|}{$\begin{array}{l}\text { Overweight } \\
\text { (7-11.5 Kg) } \\
\mathrm{N}=04\end{array}$} & \multicolumn{2}{|c|}{$\begin{array}{l}\text { Obese } \\
(5-9 \mathrm{Kg}) \\
\mathrm{N}=01\end{array}$} \\
\hline & $\mathbf{F}$ & $\%$ & $\mathbf{F}$ & $\%$ & $\mathbf{F}$ & $\%$ & $\mathbf{F}$ & $\%$ \\
\hline Within the recommended value & 5 & 38.46 & 6 & 50 & 1 & 25 & - & - \\
\hline Below the recommended value & 8 & 61.53 & 4 & 33.33 & - & & - & - \\
\hline Above the recommended value & - & - & 2 & 16.66 & 3 & 75 & 1 & 100 \\
\hline
\end{tabular}


According to U.S Institute of Medicine (IOM) issues guidelines that are followed by doctors around the world, For women who were underweight before becoming pregnant the recommended weight gain should be between 12.5-18 kg during pregnancy and for those who had a normal weight before becoming pregnant recommended weight gain is to be between 11.5- $16 \mathrm{~kg}$ during pregnancy and women who were over-weight before becoming pregnant for those recommended weight gain is between $7-11.5 \mathrm{~kg}$ and for obese women it should be $5-9 \mathrm{~kg}$ during pregnancy. As per the data shown in Table-5 it can be checked that in case of underweight women only $38 \%$ were there who had put on the weight as per the norms of IOM. In case of normal women $50 \%$ were found within the range of recommended value. There were only $25 \%$ women who gained appropriate weight as per the guidelines of IOM whereas there were $75 \%$ women who gained more than the recommended value. Also in case of obese women cent percent women were gained the weight above the recommended value.

\section{CONCLUSION}

The nutritional status of women when becoming pregnant and during pregnancy can have significant influence on both fetal, infant and maternal health outcomes. Micronutrient deficiencies such as calcium, iron, vitamin A and iodine can lead to poor maternal health outcomes and pregnancy complications which put the mother and baby at risk. Poor maternal weight gain in pregnancy due to an inadequate diet, increases the risk of premature delivery, low birth weight and birth defects.

Nutritional education and counselling seek to improve nutrition practices before and during pregnancy to improve maternal nutrition and reduce the risk of poor health outcomes in both mother and their children. Nutrition education and counselling focus on enhancing the quality of the diet, the educating women on food and what quantities they need to consume in order to achieve optimal dietary intake. This can also include counselling on the use of micronutrient supplements recommended during pregnancy, such as multiple micronutrient supplements containing iron and folic acid.

\section{REFERENCES}

[1] Ojo and Biggs EB (2010), a text book for midwives in the tropics. Second edition, bounty press Ltd, lbadan, Nigeria. Pp-50-57.

[2] Ogunjuyigbe P, Ojofietimil Eo, sanusi SA, Akinlo AA, liasu SA, Owalabi OO (2008). Food aversion.

[3] Hytten, F.E. and Lietch, I (1971). Weight gain pregnancy. The physiology of human pregnancy. Black well scientific publisher, pp. 279- 278.

[4] Jewell D. and Young G. (2003) intervention for nausea and vomiying in early pregnancy.

[5] Ojo and biggs EB (2010), a text book for midwives in the tropics. Second edition, bounty press Ltd, lbadan, Nigeria. Pp-50-57.

[6] Hareyan A (2005), psychological factor or diet durine pregnancy. Hopkin Bloomberg school of public health, USA john. Pp. 200-210. 